\title{
Validating the Variability of Snow Accumulation and Melting From GPS-Reflected Signals: Forward Modeling
}

\author{
Nasser Najibi, Shuanggen Jin, Member, IEEE, and Xuerui Wu
}

\begin{abstract}
The variability of snow accumulation and melting is one of the most important interactions of the Earth's surface with atmosphere through energy transmission and mass balance. In this paper, the effects of snow accumulation and melting together with bare soil and fixed snow depth on the reflected global positioning system (GPS) signals are investigated using GPS antenna gains and multipath signal. The reflected GPS signals are modeled and employed to analyze the interactions of snow accumulation, snow melting, bare soil, and fixed snow depth at BAKE and KUUJ GPS stations in Northern Canada. The results show the clear independency of the snow accumulation and melting variations with bare soil and fixed snow depth, which are validated from GPS-reflected signals as well. The modeled reflected GPS signals indicate the higher frequency of snow accumulation and snow melting than that of bare soil and fixed snow depth, while the estimated power spectral density of the GPS-reflected signals shows the higher signal power of coherence function difference. Furthermore, the GPS observations at BAKE and KUUJ sites confirm such variations with a good agreement during the snow accumulation, melting, bare soil, and fixed snow depth on the ground.
\end{abstract}

Index Terms-GPS-reflected signals, power spectral density, snow accumulation, snow melting.

\section{NOMENCLATURE}

FFT Fast Fourier transform.

GPS Global positioning system.

GPS-L4 GPS ionospheric geometrical-free linear combination.

GPS-R GPS-reflectometry.

GNSS Global navigation satellite system.

GrIS Greenland ice sheet.

Manuscript received September 22, 2014; revised December 21, 2014 accepted February 09, 2015. Date of publication March 20, 2015; date of current version May 29, 2015. This work was supported in part by the the National Keystone Basic Research Program (MOST 973) under Grant 2012CB72000, in part by the Shanghai Science and Technology Commission Project under Grant 12DZ2273300, and in part by the National Natural Science Foundation of China (NSFC) Project under Grant 11173050 and Grant 11373059. (Corresponding author: Shuanggen Jin.)

N. Najibi is with the Shanghai Astronomical Observatory, Chinese Academy of Sciences, Shanghai 200030, China, and also with the City University of New York, New York, NY 10031 USA.

S. G. Jin is with the Key Laboratory of Planetary Sciences, Shanghai Astronomical Observatory, Chinese Academy of Sciences, Shanghai 200030, China, and also with Bulent Ecevit University, Zonguldak 67100, Turkey (e-mail: sgjin@shao.ac.cn).

X. R. Wu is with the Shanghai Astronomical Observatory, Chinese Academy of Sciences, Shanghai 200030, China.

Color versions of one or more of the figures in this paper are available online at http://ieeexplore.ieee.org.

Digital Object Identifier 10.1109/TAP.2015.2414950
NOAA National Oceanic and Atmospheric Administration. PSD Power spectral density.

SD Snow depth.

SNR Signal-to-noise ratio.

SOPAC Scripps orbit and permanent array center.

WMO World Meteorological Organization.

\section{INTRODUCTION}

A CONSIDERABLE part of the Earth's surface is occupied by the cryosphere, including the frozen hydrosphere (sea ice, lake, and river ice), extremely thick ice bodies (ice sheets, glaciers, and icebergs), and snowpack forms (snowcovered surface, permafrost, and icy frozen ground) [1]. These places are commonly located far from human inhabitations with very severe climatic conditions, which are very difficult to measure their variations using traditional techniques [2]. Since cryospheric surfaces have special surface reflectance characteristics, they significantly affect the energy and mass balance exchange between the Earth's surface and the atmosphere [3]. Furthermore, the recently melting ice sheets can result in the sea level rise and cause the catastrophic problems on both humankinds and environment [4]. Therefore, it is very necessary to monitor snow depth changes and investigate the physical variations of snowy surfaces using available remote sensing techniques and methodologies.

Normally antennas of global navigation satellite system (GNSS) were designed for reduced low-angle multipath [5]-[7], and nowadays, the reflected GNSS signals have been exploited to remotely measure geophysical parameters of the Earth's surface [8], [9], such as sea surface features [10], coastal and lake level changes [11], [12], soil moisture [13]-[15], vegetation growth [16], forest biomass [17], and volcanic ash plumes [18]. Also, GNSS-reflectometry can be used to study the snow depth estimation, snow water equivalent [19], [20], and snow surface temperature [21]. However, the majority of recent studies were focused on the capabilities of geophysical parameters retrieval (e.g., soil moisture and snow depth) and methods. For example, Wiehl et al. [22] developed a mathematical approach using neighboring frequency bands of radar altimetry and ground-penetrating radar to remotely sense the ice sheets based on the GPS signal reflections from a rough and penetrating medium. Afterward, the dry snow density with the GPS L1 frequency was estimated [23]. Larson et al. [19] introduced the estimation of dry snow depth using signal-to-noise ratio (SNR) data for a snow-covered surface surrounding the 
ground GPS receiver derived from specified satellite elevation angles. The vegetation growth around the GPS antenna was estimated through employing the multipath analysis using SNR data [16]. Moreover, Nievinski et al. [24] formulated both forward and inverse methodology for snow depth estimation from GPS SNR observations using GPS multipath reflectometry (GPS-MR) approach and then validated the retrieval algorithms by comparing the results with in situ data observed at three different GPS locations including grasslands, alpine, and forest [25]. McCreight et al. [26] used SNR observable recorded by GPS instruments as multipath to derive snow and snow water equivalent.

However, not all GPS receivers provide the SNR values due to the limitation in the data storage capacity. Another way is to get the multipath through the ionopsheric-free geometrical linear combinations of GPS signals. Ozeki and Heki [27] estimated snow depth at Shinshinotsu site (located in Hokkaido, Japan) using free geometrical linear combinations of GPS signals. Furthermore, snow surface temperature was estimated in two GNSS permanent stations named SMM1 and MARG at Greenland Ice Sheet (GrIS) using both GPS-L4 and thermophysical behavior of snow layer variability technique with mean bias of $0.18^{\circ} \mathrm{C}$ and $3.8^{\circ} \mathrm{C}$, respectively [21].

In this paper, the effects of snow accumulation and snow melting (the change in snow depth) as well as bare soil and stable snow on the ground (the stable phase condition) on GPS-reflected signals are investigated and discussed by analyzing the physical reflectivity around the GPS receivers in Northern Canada. The theory and method are presented in Section II, GPS observations and meteorological data are shown in Section III, results and discussion are presented in Section IV, and finally conclusion is given in Section V.

\section{Theory AND Methodology}

\section{A. GPS Signals Reflected From the Surroundings of Ground GPS Station's Surfaces}

1) Contribution of GPS-Reflected Signals to GPS Carrier Phase: The reflected signals from GPS receiver are carried by a time delay when they arrive at the GPS receiver antenna. This will result in a phase shift on the received GPS signals by the antenna. If the entire signals can be received by GPS receiver antenna as $E$, including the scattered signals $(S)$ and the reflected signals $(R)$, the GPS observable at the time $t$ will be as follows [28]:

$$
E(t)=S(t)+R(t)
$$

Substituting by $S(t)=S_{0} e^{-2 \pi i f t}$, it gives

$$
E(t)=S(t)+R(t)=S_{0} e^{-2 \pi i f t}+\alpha S_{0} e^{-2 \pi i f(t+\delta \Phi)}
$$

where $S_{0}$ denotes the original amplitude of GPS signal, i stands for imaginary unit ( $\mathrm{i} 2=-1)$, $\mathrm{f}$ is the frequency of GPS carrier phase signal, $\alpha$ denotes the attenuation factor that depends on the reflected surface (change in the amplitude of received signal by antenna; $0 \leq \alpha \leq 1)$ and $\delta \Phi$ is the change occurred in the phase of received signal from the reflected surface. Equation (2) has two important items, the reflected phase shift value $(\delta \Phi)$ and the reflected surface characteristic $(\alpha)$, which provide us with enough information about the reflected surface through the reflected signal. Accordingly, in order to exclude $\delta \Phi$ from (2), it is given by considering $N=4 \pi \lambda^{-1} \sin (\varepsilon)$, where $\lambda=\mathrm{cf}^{-1}$ ( $c$ is the speed of the light) [29] as

$$
\delta \Phi(\alpha, N, H)=\tan ^{-1} \frac{\alpha \sin (N H)}{1+\alpha \cos (N H)}
$$

where $H$ is the height of GPS antenna (note that $\mathrm{H}$ is different from the length of GPS antenna in the case where the situations around the GPS antenna are being changed continuously) and $\mathrm{f}$ is the corresponding GPS dual-frequency signals ( $\mathrm{L} 1=1575.42, \mathrm{~L} 2=1227.60 \mathrm{MHz}$ ). Importantly, (3) describes that the reflected phase shift depends critically on $\mathrm{H}$ and any changes can result in a specified value in $\delta \Phi$. In a similar way, the reflected phase shift values for a specified time span and a determined surface will be concluded totally as follows:

$$
\delta \Phi_{i}(\alpha, N, H)=\tan ^{-1} \frac{\sum_{i=1}^{K} \alpha_{i} \sin \left(N_{i} H_{i}\right)}{1+\sum_{i=1}^{K} \alpha_{i} \cos \left(N_{i} H_{i}\right)}
$$

where $\mathrm{K}$ is the entire number of reflected signals from the objective surface.

2) Ionospheric Geometrical-Free Linear Combination of GPS Signals (GPS-L4): There are several combinations of GPS observations (code pseudorange, carrier phase, and Doppler) and a suitable combination can be advantageous for understanding and solving the GPS-related problems [30]. However, using the ionospheric geometrical-free linear combination is more practical because of eliminating the most effects of the ionosphere on the GPS signals. The GPS ionospheric geometrical-free linear combination (GPS-L4) $\Phi \mathrm{IF}$ of carrier phase signals is proposed as follows [21]:

$$
\text { GPS-L4 }=\Phi_{\mathrm{IF}}=-\frac{f_{1}^{2}}{f_{1}^{2}-f_{2}^{2}} \times \Phi_{1}+\frac{f_{2}^{2}}{f_{1}^{2}-f_{2}^{2}} \times \Phi_{2}
$$

where $\mathrm{f} 1$ and $\mathrm{f} 2$ denote the GPS frequencies (f1 = $1575.42 \mathrm{MHz}, \mathrm{f} 2=1227.60 \mathrm{MHz}$ ), and $\Phi 1$ and $\Phi 2$ are the GPS dual-frequency carrier phase signals. Although the geometric information has been canceled out by taking the difference, $\Phi I F$ is geometry-free as well [21], [27].

\section{B. Variability of GPS-Reflected Signals From Ground GPS Station's Surfaces}

Although the reflected phase shift values are important for analyzing the GPS-reflected signals, the more important is the variability of reflected phase shift values especially with respect to the GPS antenna height changes, which is necessary to infer the variability of physical situation around the ground GPS receiver. The physical reflectivity of ground GPS receiver environment with respect to GPS antenna height can be retrieved as

$$
\frac{d \delta \Phi}{d H}=\frac{V_{\delta \Phi}}{V_{H}}=N \alpha \frac{(\cos (N H)+\alpha)}{(\alpha+\cos (N H))^{2}+\sin ^{2}(N H)}
$$


where $\mathrm{V} \delta \Phi$ and $\mathrm{VH}$ are, respectively, the variability of $\delta \Phi$ and $\mathrm{H}$ with reference to the specified time span [29] and $\mathrm{N}$ is the same term defined in (3). As it is clear in (6), the variability of reflected phase shift with respect to $\mathrm{H}$ variations depends mostly on $\mathrm{N}$ (and thus on $\varepsilon$ ), though the embedded $\mathrm{H}$ in every term in (6) illustrates that by considering a specified value for $\varepsilon$ (e.g., $\varepsilon=30^{\circ}, 45^{\circ}$, or $60^{\circ}$ ), $\mathrm{H}$ contributes significantly to the physical reflectivity of ground GPS receiver's surroundings. In a similar manner, the variability of GPS-L4 with respect to the changes on the GPS antenna height for each wavelength of $\lambda 1$ and $\lambda 2$ of GPS dual-frequency signals $(\lambda 1=0.1902$ and $\lambda 2=$ $0.2442 \mathrm{~m}$ ) is derived as

$$
\begin{aligned}
\frac{d L 4(\varepsilon, \alpha, H, f)}{d H} \cong & \frac{d \delta \Phi(\varepsilon, \alpha, H, \lambda)}{d H} \\
= & -\frac{f_{1}^{2}}{f_{1}^{2}-f_{2}^{2}} \times \frac{d \delta \Phi}{d H}\left(\alpha, \varepsilon, H, \lambda_{1}\right) \\
& +\frac{f_{2}^{2}}{f_{1}^{2}-f_{2}^{2}} \times \frac{d \delta \Phi}{d H}\left(\alpha, \varepsilon, H, \lambda_{2}\right)
\end{aligned}
$$

where $\frac{d \delta \Phi}{d H}$ is defined in (6).

\section{Physical Reflectivity of Snow-Covered Surfaces With GPS Signals}

1) Snow Accumulation and Snow Melting: A complete study of polarization reflectance of snow and ice surface's reaction to the GPS-scattered L1 and L2 signals as well as the physical reflectivity of these surfaces with respect to the variability of satellite elevation angles and GPS antenna heights are given in detail in [29] and [31]. The satellite elevation angle and GPS antenna height are the most effective factors in the physical reflectivity of GPS-reflected signals. However, GPS antenna height is the main parameter for physical reflectivity of snowy and icy surfaces in certain satellite elevation angles or the average of all the possible satellite elevation angles.

In order to better understand the interaction of snow depth changes (accumulation or melting) with GPS signals and the possible variations in GPS antenna height, Fig. 1 presents a schematic picture of this procedure. According to this, the following straightforward equation can be written among GPS antenna height $(\mathrm{H})$, GPS antenna length (L) (analogous to the original GPS antenna height), and snow depth changes (h) as

$$
H=L-h .
$$

In (8), it is clear that snow accumulation (when $\mathrm{h}$ is increasing) and snow melting (when $\mathrm{h}$ is decreasing) will result in decrease and increase in $\mathrm{H}$, respectively, while the GPS antenna length (L) is being fixed and irreplaceable continuously. It should be noted here that $\mathrm{H}$ is completely different from GPS antenna length (L) in a dynamic climate conditions such as snow falling and ablation seasons.

2) Bare Soil and Stable Snow on the Ground: As it is mentioned in (8), the snow depth changes (h) contribute to different values in GPS antenna height $(\mathrm{H})$. Accordingly, during a specified time span in the stable situation for $\mathrm{h}$, which is essentially

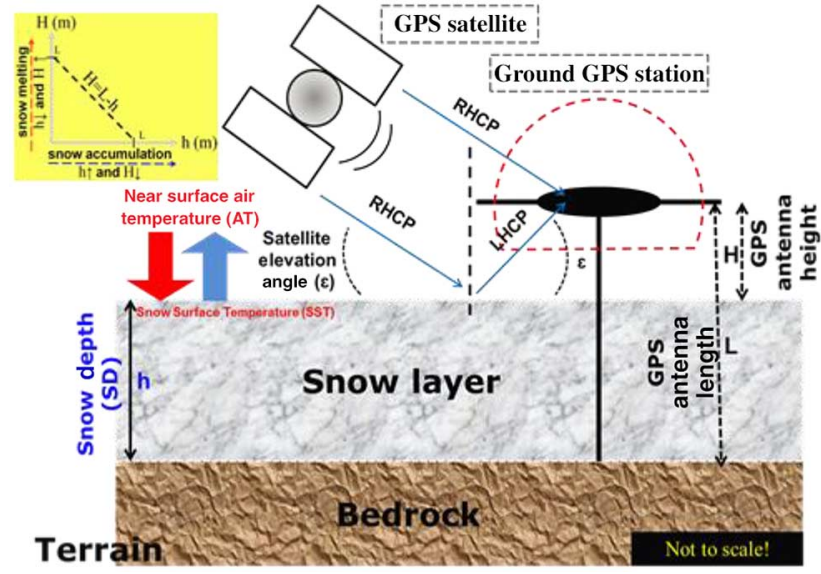

Fig. 1. Interaction of snow depth (height) changes existed surroundings of the ground GPS station with GPS signals (not to scale).

based on a fixed value for snow depth (e.g., $\mathrm{h}=0.25 \mathrm{~m}$ ) and bare ground $(h=0), H$ will get certain value mostly due to $L$. In fact, in a constant environment situation around the ground GPS station, mostly the satellite elevation angle $(\varepsilon)$ variations results in changes on GPS-reflected signals as demonstrated by Najibi and Jin [29]. In the following sections, forward modeling of GPS-reflected signals and GPS-L4 as well as its evaluation by real GPS observations for different scenarios of snow depth changes will be discussed in detail.

\section{GPS And Meteorological Observations}

\section{A. GPS Observations Stations}

In order to analyze the effects of GPS-reflected signals on ground GPS station surroundings, two GPS stations from International GNSS Service (IGS) stations in Northern Canada are used (BAKE and KUUJ). Northern Canada has a dynamic climate status particularly in existence of an immense snow and vast ice on the ground in cold seasons, and there is rare snowcovered surface on the ground in spring season. Therefore, this dynamic climate would affect directly on the GPS-reflected signals variability either through carrier phase observations or linear combination of them.

The BAKE and KUUJ GPS stations have been equipped with a receiver type of AOA-BENCHMARK-ACT and an antenna type of AOAD/M_T and TPSCR.G3, respectively. These GPS receivers can receive dual-frequency observations per $30 \mathrm{~s}$ continuously, so the observations of daily 2880 epochs from 32 satellites are collected for 3 years from January 01, 2010 to December 31, 2012. In this study, the average daily GPS-L4 values from all the feasible observed satellites are used without removing any epochs or limiting the computations upon special satellite(s) number.

\section{B. Meteorological Data}

Hourly snow depth (SD) measurements are collected at the meteorological stations BAKER and KUUJ. According to the 
metadata, the instruments used for these meteorological stations are generally obtained from Campbell-Scientific by calibration according to the World Meteorological Organization (WMO) standards. Moreover, the meteorological stations have also been equipped with automatic weather measurement instruments operating by the Meteorological Service of Canada. The $\mathrm{SD}$ values are obtained as average daily ones. The meteorological data have been provided partly by National Climatic Data Center (NCDC) of National Oceanic and Atmospheric Administration (NOAA) as well as National Climate Data and Information Archive (NCDIA), Meteorological Service of Canada, Environment Canada. The GPS and meteorological stations are co-located approximately with BAKE site (longitude: $-96.01^{\circ}$, latitude: $64.32^{\circ}$ ) and KUUJ site (longitude: $-77.75^{\circ}$, latitude: $55.28^{\circ}$ ), while the GPS and meteorological stations are about 0.29 and $0.35 \mathrm{~km}$ far from each other, respectively.

\section{Results And Discussions}

The flowchart of validating the snow accumulation and melting and also fixed Earth surface (bare soil and stable snow on the ground) with GPS-reflected signals are shown in Fig. 2. Each step is discussed in detail as follows:

\section{A. Effects of Snow Depth Changes, Bare Soil, and Stable Snow on GPS-Reflected Signals}

In general, the snow accumulation and snow melting causes lengthy changes on the GPS antenna height placed in this area increasingly or decreasingly. The GPS antenna length is a fixed value and might not be changed, unless the new GPS antenna with different length is being replaced. In fact, the GPS antenna height depends on the existing physical environment surrounding the ground GPS receiver. Consequently, as presented in Fig. 1, $\mathrm{H}$ is being affected by the changes of h. Furthermore, Section II shows the direct relation between $\mathrm{H}$ and $\mathrm{h}$ based on the snow depth changes.

Based on this, by considering (4) and (6) together, Fig. 3 illustrates, respectively, the snow accumulation (left) and snow melting (right) effects on the reflected GPS signal phase shift $(\delta \Phi)$ and variability of physical reflectivity surrounding GPS receiver with respect to GPS antenna height variation $(\mathrm{d} \delta \Phi / \mathrm{dH})$. As it can be seen in Fig. 2, the frequency of $\delta \Phi$ is increasing while the satellite elevation angle is increasing; e.g., $\delta \Phi$ is fluctuating more in $\varepsilon=60^{\circ}$ than $\varepsilon=30^{\circ}$. The latter statement is also true for the trend of $\mathrm{d} \delta \Phi / \mathrm{dH}$. In addition, the amplitude of $\mathrm{d} \delta \Phi / \mathrm{dH}$ is increasing while the higher $\varepsilon$ is employed; for instance, it is twice for $\varepsilon=60^{\circ}$ rather than $\varepsilon=30^{\circ}$, approximately.

In a similar manner, if we consider the physical reflectivity of GPS signals derived from bare soil $(\mathrm{h}=0$ which is analogous to $h=L$ [29]) and stable snow on the ground (e.g., $\mathrm{h}=0.25 \mathrm{~m}$ ), the corresponding values can be presented as in Fig. 4. Although there is no origin-reflected phase shift signals from the bare soil, their variability in the range of $\varepsilon$ (here between $10^{\circ}$ and $90^{\circ}$ ) is increasing as $\varepsilon$ is increasing

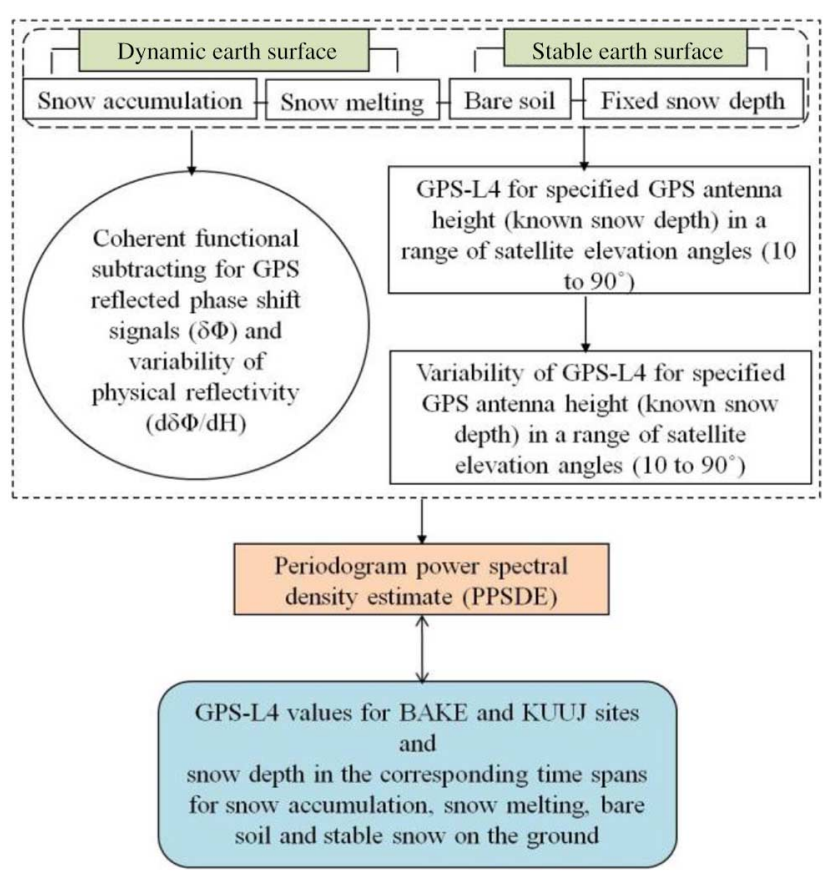

Fig. 2. Flowchart in validating snow depth changes (accumulation, melting and or bare soil, and stable snow on the ground) using GPS-reflected signals.
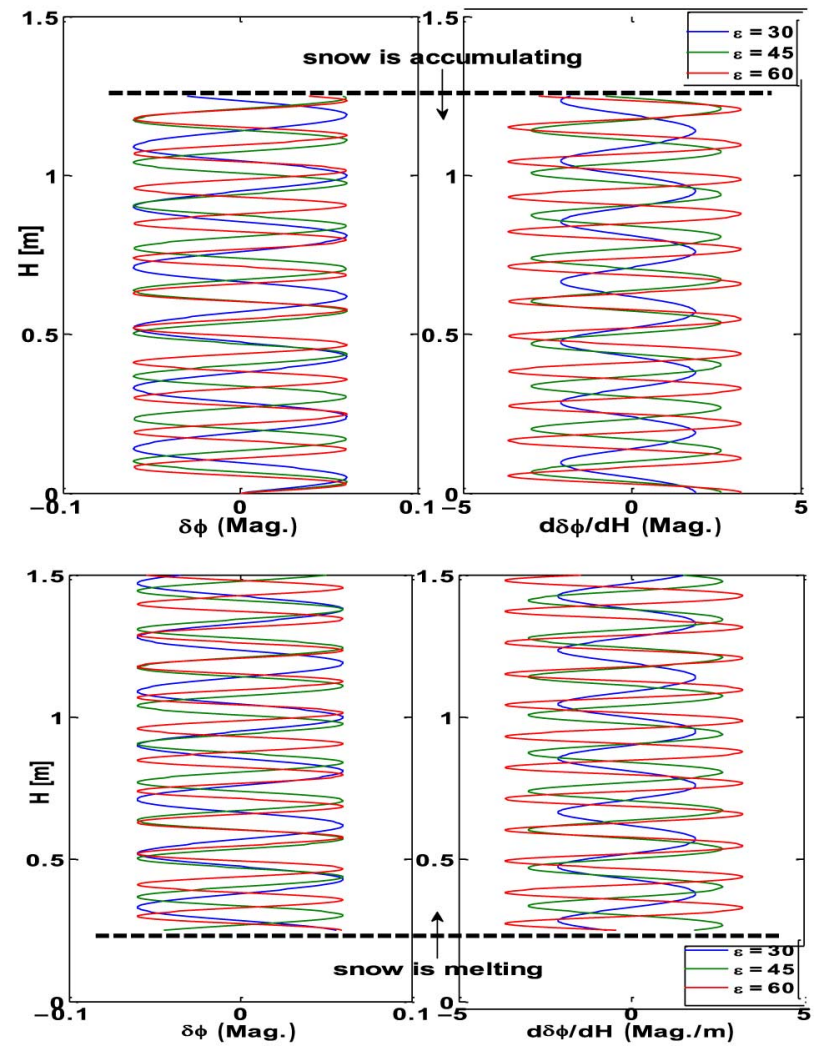

Fig. 3. GPS-reflected signal phase shift ( $\delta \Phi[$ Mag.]) (left) values and the variability of physical reflectivity from the surrounding GPS receiver based on the GPS antenna height changes ( $\mathrm{d} \delta \Phi / \mathrm{dH}[\mathrm{Mag} . / \mathrm{m}])$ due to snow accumulation (in left, the maximum snow depth is $1.25 \mathrm{~m}$ ) and snow melting (in right, the initial snow depth is assumed to be $1.25 \mathrm{~m}$ ) with different satellite elevation angles and the GPS antenna length is considered as $1.5 \mathrm{~m}$. 

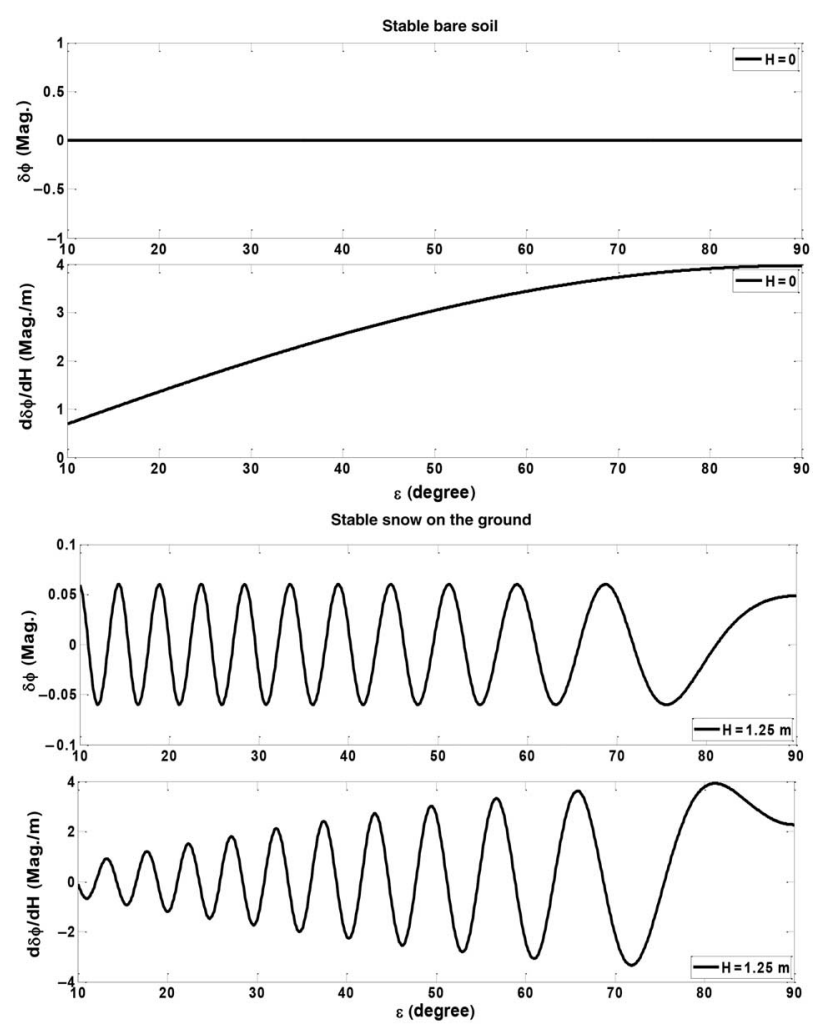

Fig. 4. GPS-reflected signal phase shift ( $\delta \Phi$ [Mag.]) values and the variability of physical reflectivity from the GPS receiver based on GPS antenna height changes ( $\mathrm{d} \delta \Phi / \mathrm{dH}[\mathrm{Mag} . / \mathrm{m}])$ due to stable bare soil (top) and fixed snow depth on the ground in different satellite elevation angles; the GPS antenna length is considered as $1.5 \mathrm{~m}$ and initially there is $0.25 \mathrm{~m}$ snow on the ground.

continuously. For the constant snow depth on the ground, the amplitude of $\mathrm{d} \delta \Phi / \mathrm{dH}$ is steadily increasing considerably while its frequency is being fixed approximately. As an example, for $\varepsilon=20^{\circ}$, the $\delta \Phi$ and $\mathrm{d} \delta \Phi / \mathrm{dH}$ are equal to -0.04 [Mag.] and -1 [Mag./m] respectively, but $\delta \Phi=-0.02$ [Mag.] and $\mathrm{d} \delta \Phi / \mathrm{dH}=-2.8[\mathrm{Mag} . / \mathrm{m}]$ for $\varepsilon=60^{\circ}$.

\section{B. Variability of GPS-L4 Values Caused by Snow Depth Changes}

According to Section II-A2, by considering (3) and (5), the GPS-L4 values in different satellite elevation angles for snow depth variations (e.g., $\mathrm{H}=0.75 \mathrm{~m}$ ), stable snow on the ground, and bare soil can be modeled as in Fig. 5. It is clear that the frequency of GPS-L4 values is increasing while the physical conditions surrounding the GPS receiver are changing through the increase in the GPS antenna height. Although its amplitude is approximately fixed, GPS-L4 is very sensitive to the caused changes physically on initial situation $(\mathrm{h}=0$ and thus $\mathrm{H}=\mathrm{L}$ ) around GPS receiver. Importantly, the GPS-L4's amplitude in each case (bare soil, snow depth changes, and stable snow depth) is greater for those higher satellite elevation angles than lower angles. This can be described for a unique surface in a very short-specified time span. As the satellite elevation angle is enhancing, the percentage of strengthened reflected signals would be increased.

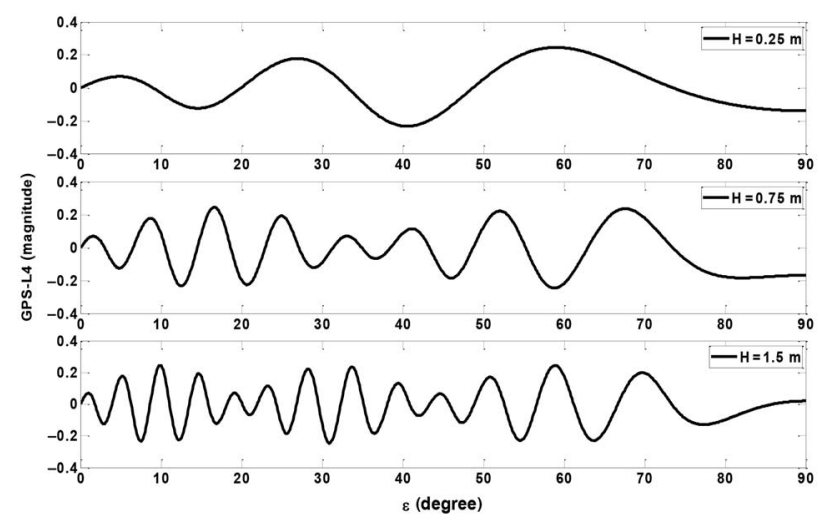

Fig. 5. GPS-L4 values for bare soil $(\mathrm{h}=0 ; \mathrm{H}=1.5 \mathrm{~m})$, snow depth changes $(\mathrm{h}=0.75 ; \mathrm{H}=0.75 \mathrm{~m})$, and stable snow on the ground $(\mathrm{h}=1.25$; $\mathrm{h}=0.25 \mathrm{~m}$ ) in different satellite elevation angles $(\varepsilon)$ (the GPS antenna length is assumed as $1.5 \mathrm{~m}$ )

\section{Coherence Functional Subtracting of GPS-Reflected Signals and GPS-L4 Variability}

In order to pay more attention to the effects of both snow accumulation and melting as well as both bare soil and fixed snow depth on the ground, the difference between modeled GPS-reflected phase shift value and its variability with respect to GPS antenna height variation is proposed based on coherence functional subtracting. Although the mentioned scenarios are occurring in different timing spans and $\mathrm{H}$ values, the calculations of coherence functional subtracting are being done here only for the sharing $\mathrm{H}$ values (for either cases when $\mathrm{H}$ increases or decreases). In fact, it is reasonable only to apply the coherence functional subtracting between those modeled signals in the same physical condition span ranges. Based on this, Fig. 6 represents the output signals for three selected satellite elevation angles $\left(\varepsilon=30^{\circ}, 45^{\circ}\right.$, and $\left.60^{\circ}\right)$ derived from the signal coherence functional subtraction between snow accumulation and melting scenarios (which were shown earlier in Fig. 2).

It is clear that the signal amplitude for $\mathrm{d} \delta \Phi / \mathrm{dH}$ is extremely greater than $\delta \Phi$ during the calculations of the snow accumulating and melting signal subtraction. Moreover, $\mathrm{d} \delta \Phi / \mathrm{dH}$ for $\varepsilon=60^{\circ}$ (high satellite elevation angles) has greater values than $\varepsilon=45^{\circ}$ and then $\varepsilon=30^{\circ}$ (low satellite elevation angles). This demonstrates that the sensitivity of $\mathrm{d} \delta \Phi / \mathrm{dH}$ for high satellite elevation angles is more than lower angles. Similarly, GPSL4's amplitude is greater for those higher satellite elevation angles than the low angles. Additionally, the difference (coherence functional subtracting) between modeled GPS-reflected phase shift value and its variability with respect to GPS antenna height variation for both stable bare soil and fixed snow depth on the ground is analyzed. The $\mathrm{d} \delta \Phi / \mathrm{dH}$ values are increasing as the $\varepsilon$ is increasing, but the frequency is decreasing simultaneously. The latter can be seen for $\delta \Phi$ as well. It is clear that the GPS-reflected signals values and their variabilities for a fixed physical phase body (bare soil or stable snow depth) only depend on satellite elevation angle variations. In fact, this situation is happening by considering $\mathrm{H}$ as a constant value, though this initial constant value for $\mathrm{H}$ plays a critical role in the 


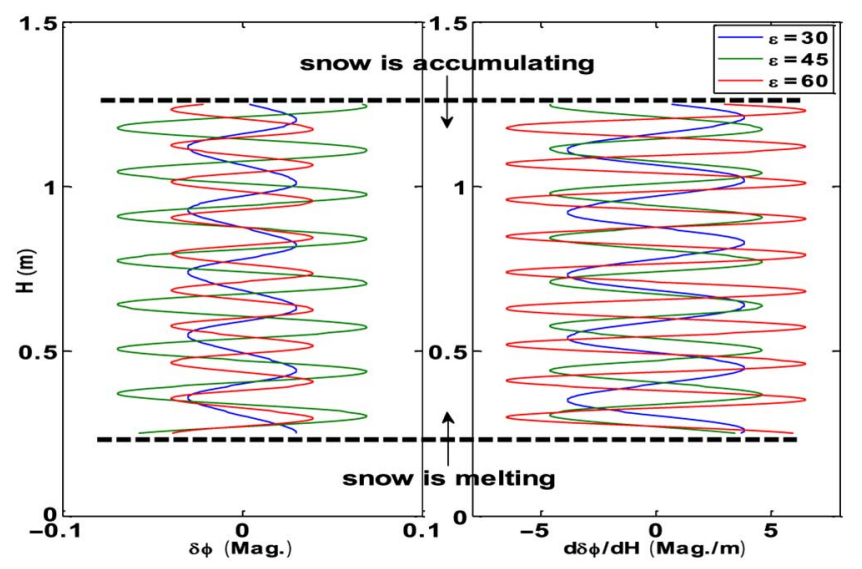

Fig. 6. Coherence functional subtracting of GPS-reflected signal phase shift $(\delta \Phi$ [Mag.]) (left) values and the variability of physical reflectivity from the surrounding GPS receiver based on the GPS antenna height changes $(\mathrm{d} \delta \Phi / \mathrm{dH}$ [Mag./m]) (right) between snow accumulation and melting during shared $H$ span (the shared span is considered here when there is $0.25 \mathrm{~m}$ snow on the ground till melting of $1.25 \mathrm{~m}$ snow) in different satellite elevation angles; the GPS antenna length is considered as $1.5 \mathrm{~m}$.

amplitude and frequency of GPS-reflected signals for different satellite elevation angles.

Although $\mathrm{d} \delta \Phi / \mathrm{dH}$ depends critically on GPS antenna height variation in snow accumulation and melting studies, the variability of GPS-L4 is significantly describing the changes in the GPS antenna height. Moreover, GPS-L4 is mostly standing for the magnitude (power) of the GPS-reflected signals. In other words, variability of GPS-L4 with respect to $\mathrm{H}$ variations can demonstrate the $\mathrm{d} \delta \Phi / \mathrm{dH}$ variations in different satellite elevation angles. Therefore, GPS-L4 can be applied when there is a possibility to have a dual-frequency GPS receiver. The variability of GPS-L4 values show clearly the two consequent peaks derived from GPS L1 and L2 carrier phase signals. These peaks can be found also in [44] where the larger antenna heights resulted in higher frequency multipath signatures. Accordingly, here $\mathrm{H}=1.25 \mathrm{~m}$ has higher frequency for the variability of GPS-L4 values especially with great signal amplitudes in high satellite elevation angles. In addition, it has already been presented in Fig. 4 that the increase in $\mathrm{H}$ will result in increase in the frequency of GPS-L4 variability, and thus, low $\mathrm{H}$ values have less modulated signals.

\section{Case Studies}

The average GPS-L4 values based on (5) for all possible GPS L1 and L2 carrier phase observables (not limited to special satellite elevation angles) are computed daily for 3 years (2010, 2011, and 2012) in both BAKE and KUUJ sites. The daily SD values from the meteorological center located near BAKE and KUUJ GPS stations are prepared and processed as well. For example, Fig. 7 represents the variability of SD and GPS-L4 for snow accumulation season (October, November, and December) and snow melting season (April, May, and June) and fixed snow on the ground (January) and bare soil (July) for BAKE site in 2011 with the good statistical variation characteristics of the variability. Similarly, KUUJ site also shows the SD and GPS-L4 variability for snow accumulation season

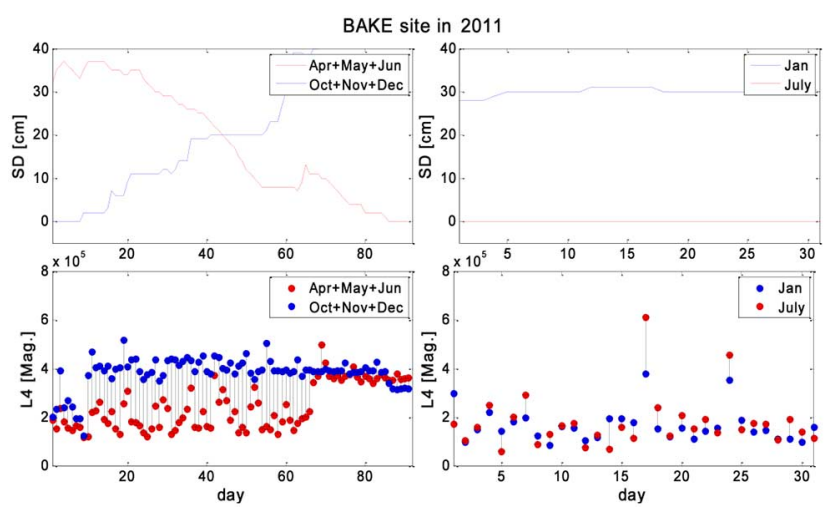

Fig. 7. Variability of snow depth (SD) and GPS-L4 values for snow accumulation season (October, November, and December) and snow melting season (April, May, and June) and stable snow on the ground (January) and stable bare soil (July) for BAKE site in 2011.

TABLE I

Average of GPS-L4 VAlues FOr SNOW ACCUMUlation AND Melting As Well as Bare Soil and Stable Snow Depth on the GROUND IN BAKE AND KUUJ Sites (UNIT: [DB])

\begin{tabular}{|c|c|c|c|c|c|c|}
\hline $\begin{array}{c}\text { GPS } \\
\text { Station }\end{array}$ & \multicolumn{3}{|c|}{ BAKE } & \multicolumn{3}{|c|}{ KUUJ } \\
\hline Year & 2010 & 2011 & 2012 & 2010 & 2011 & 2012 \\
\hline $\begin{array}{c}\text { Snow } \\
\text { accumula } \\
\text { tion and } \\
\text { melting }\end{array}$ & $\begin{array}{c}18.46 \times \\
10^{4}\end{array}$ & $\begin{array}{c}14.74 \times \\
10^{4}\end{array}$ & $\begin{array}{c}12.71 \times \\
10^{4}\end{array}$ & $\begin{array}{c}18.48 \times \\
10^{4}\end{array}$ & $\begin{array}{c}9.74 \times \\
10^{4}\end{array}$ & $\begin{array}{c}13.01 \times \\
10^{4}\end{array}$ \\
\hline $\begin{array}{c}\text { Bare soil } \\
\text { and stable } \\
\text { snow }\end{array}$ & $\begin{array}{c}4.14 \times 1 \\
0^{4}\end{array}$ & $\begin{array}{c}5.01 \times 1 \\
0^{4}\end{array}$ & $\begin{array}{c}0.34 \times 1 \\
0^{4}\end{array}$ & $\begin{array}{c}3.93 \times 1 \\
0^{4}\end{array}$ & $\begin{array}{c}3.77 \times \\
10^{4}\end{array}$ & $\begin{array}{c}4.51 \times 1 \\
0^{4}\end{array}$ \\
\hline
\end{tabular}

(October, November, and December) and snow melting season (March, April, and May) and fixed snow on the ground (January and February) and bare soil (July and August) for 2010, 2011, and 2012.

Considering the timing spans for the SD changes (accumulating and melting), there is a sizable difference between the GPS-L4 values for snow accumulation and snow melting seasons. Conversely, there is a subtle difference between the two trends of GPS-L4 values for bare soil and fixed snow depth on the ground. This difference in the mentioned scenarios for both BAKE and KUUJ sites in 2010, 2011, and 2012 can be seen in Table I. For instance, the average subtracting of GPS-L4 values for snow accumulation and melting in BAKE site for 2010 is about $18.46 \times 104[\mathrm{~dB}]$ and for bare soil and stable snow depth on the ground is $4.14 \times 104[\mathrm{~dB}]$.

In fact, the GPS-L4 values as GPS-reflected signals from surrounding GPS receiver illustrate that the changes in the GPS antenna height, which could be from snow falling and thus snow accumulating or an increase in the near surface air temperature and then leading into snow melting, are the main reason to give different values to GPS-L4. In addition, according to Fig. 6, the difference between two modeled $\mathrm{d} \delta \Phi / \mathrm{dH}$ variations for snow accumulation and melting signals are considerably large for any GPS antenna height within this time span. Moreover, the frequency of such signal is extremely high and thus the magnitude of signal (power of signal) is a large number. On the other hand, the $\mathrm{d} \delta \Phi / \mathrm{dH}$ variations for the difference between bare 


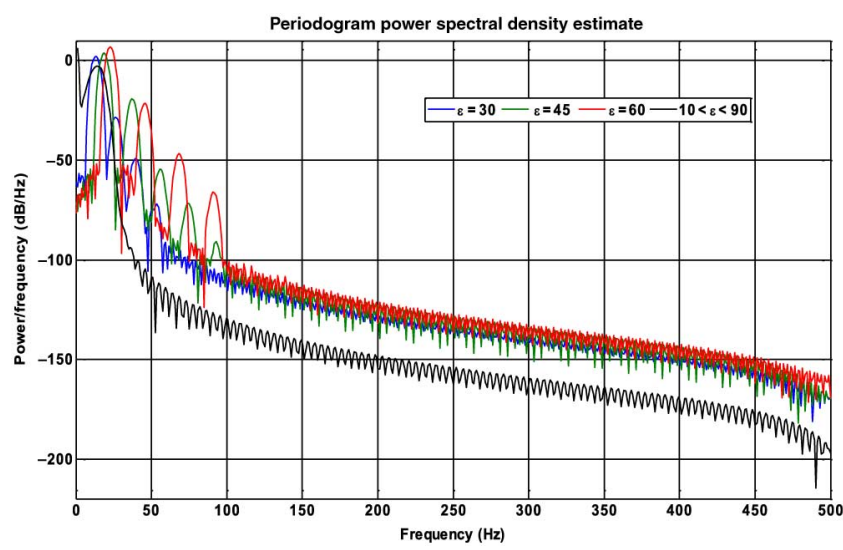

Fig. 8. Periodogram power spectral density estimate (PPSDE) for the variability of physical reflectivity based on the GPS antenna height changes for coherence functional subtracting of snow accumulation and melting (colored lines) as well as for the coherence functional subtracting of the stable bare soil $(\mathrm{H}=\mathrm{L}$ or 0$)$ and fixed snow depth $(\mathrm{H}=1.25 \mathrm{~m})$ (black line) in different satellite elevation angles between $10^{\circ}$ and $90^{\circ}$ (GPS antenna length is considered equal to $1.5 \mathrm{~m}$ ).

soil and fixed snow depth are changeable and mostly dependent on the satellite elevation angle. However, it is clear that the $\mathrm{d} \delta \Phi / \mathrm{dH}$ are large only for high satellite elevation angles but the frequency of signal is not a large number as in Fig. 6 . Therefore, the signal power cannot be a great value, especially in comparison to Fig. 6.

\section{E. Power Spectral Density of Physical Reflectivity Variability and GPS-L4 Values}

In order to validate and then compare the magnitude of GPSreflected signals derived from GPS-L4 values with modeled GPS-reflected signals with respect to the GPS antenna height changes, the power spectral density (PSD) using WienerKhinchin theorem [32] (periodogram power spectral estimate) is proposed for coherence functional subtracting of snow accumulation and melting as well as for the coherence functional subtracting of the stable bare soil $(\mathrm{H}=\mathrm{L}$ or 0$)$ and constant snow depth $(\mathrm{H}=1.25 \mathrm{~m})$. The PSD creates an estimate of the power spectrum using a windowed (analogous to a weighted matrix) fast Fourier transform (FFT) for the autocorrelation function of the inserted signal.

Fig. 8 represents the magnitude of output signal for the simulated coherence functional subtracting of physical reflectivity for the snow accumulation and melting for $\varepsilon=30^{\circ}, 45^{\circ}$, and $60^{\circ}$ and similarly for the bare soil and stable snow depth (e.g., $\mathrm{H}=1.25 \mathrm{~m}$ ) in different satellite elevation angles $\left(10^{\circ}-90^{\circ}\right)$ in a specified frequency domain. Although the power/frequency for the Fig. 6 is big, the integrated average value of the PSD for each $\varepsilon=$ $30^{\circ}, 45^{\circ}$, and $60^{\circ}$ and $10^{\circ}<\varepsilon<90^{\circ}$ on this selected frequency domain is also $12.4058,15.5465,26.1782$, and 12.2564 $[\mathrm{dB}]$, respectively. This demonstrates that PSD of the coherence functional subtracting values for the whole snow accumulation and snow melting scenarios are greater than similarly derived values for bare soil and stable snow on the ground scenarios. On the other hand, this can be validated and recognized by
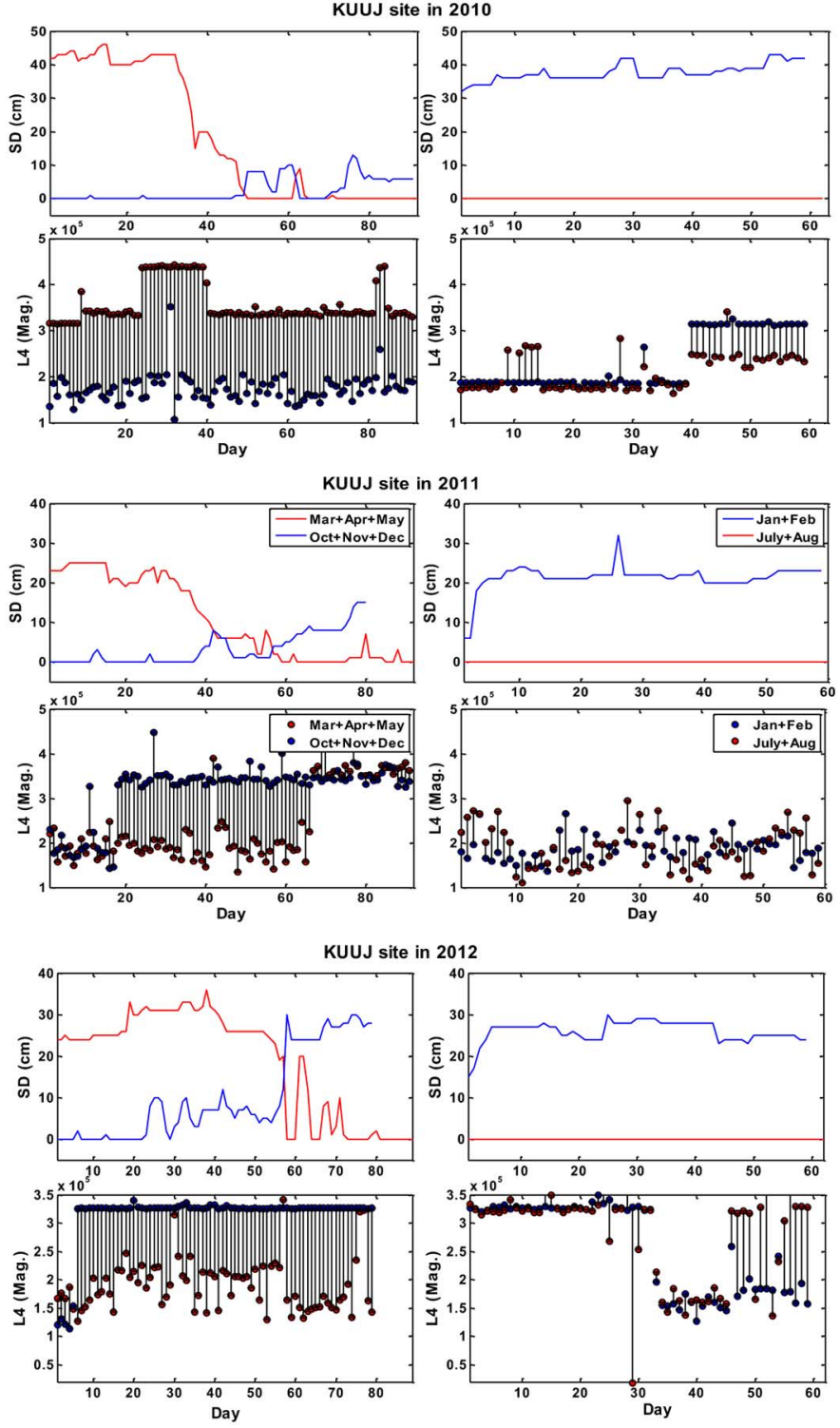

Fig. 9. Variability of snow depth (SD) and GPS-L4 values for snow accumulation season (October, November, and December) and snow melting season (March, April, and May) and stable snow on the ground (January and February) and stable bare soil (July and August) at KUUJ site in 2010 (top), 2011 (middle), and 2012 (bottom).

considering the bar-dashed length (by keeping a unique y-axis scale) between GPS-L4 in snow accumulation and snow melting for accumulation and melting seasons given in Fig. 9 (also the similar values for bare soil and stable snow) and those values given in Table I. The GPS-L4 values between snow falling and melting seasons are extremely bigger than the same values in summer and stable weather condition seasons. This illustrates that the changes caused on surrounding GPS receiver would result in different values in GPS-L4 and thus conversely the stable conditions bring about fixed GPS-L4 values approximately. However, the last statement is true for the idealistic conditions by ignoring systematic errors and the initial data transforming to average daily values instead of high temporal resolution ones. 


\section{SUMMARY AND CONCLUSION}

This study represents the effects of physical reflectivity variability around the ground GPS station surface with the existence of snow accumulation and snow melting as well as bare soil and stable snow, including the changes in reflected GPS signal phase shift $(\delta \Phi)$ and its variability $(\mathrm{d} \delta \Phi / \mathrm{dH})$ as well as GPS-L4 values. The modeled snow depth changes are showing the capability of GPS-reflected signals to sense the physical variations around the ground GPS receivers. Since in this study we do not restrict our GPS dual-frequency observations to the specified satellite elevation angles, GPS-L4 values are mostly subject to the GPS antenna height variations. Thus, GPS-L4 variations reflect the changes of existing physical situation around the ground GPS station surface and therefore the snow depth changes or static physical condition like as bare soil and stable snow around the GPS station may result in special patterns of GPS-L4 values. Therefore, the GPS-L4 values will be changed after snow accumulation and snow melting during a specified time span. The results and conclusions are summarized as follows.

1) The effect of simulated snow accumulation and snow melting scenarios on the reflected GPS signal phase shift is steady with similar pattern when compared to each other. The initial phase shift and amplitude of the derived reflected signals for both snow accumulation and snow melting scenarios are equal if we do not consider the initial phase shift and amplitude. The interaction of accumulating and melting snow on the surface with GPS signals is similar to each other in a specified time span.

2) Daily GPS-L4 observations are studied at two GPS stations in Northern Canada for snow accumulation months (October, November, and December) and snow melting ones (March, April, May, and June) in 2010, 2011 and 2012. The difference of GPS-L4 between snow accumulation and melting is constant approximately and depends on the caused changes into physical conditions surrounding GPS receiver. On the other hand, there is also a difference in the amplitude of the accumulating and melting modeling trends.

3) The modeled GPS-reflected signal phase shift values and the variability of physical reflectivity between stable bare soil $(\mathrm{h}=0 ; \mathrm{H}=\mathrm{L}$ or 0$)$ and fixed snow depth on the ground ( $\mathrm{h}=0.25 ; \mathrm{H}=1.25 \mathrm{~m}$ ) show the increasing amplitude of aforementioned trends when the satellite elevation angle is enhancing. The frequency of subtracted signals is decreasing while the satellite elevation angle is increasing simultaneously. At both BAKE and KUUJ sites, the daily GPS-L4 values for the bare soil case (July, July, and August) and fixed snow depth (January, January, and February) show a subtle difference when compared to the snow accumulation and snow melting. The interaction of GPS signals with the static surface (whether bare soil or fixed snow depth) is unique in terms of the received signal power. While in the stable case, the GPS-reflected signals depend critically on the satellite elevation angle variability rather than the constant situation around the GPS receiver.
4) The increase in the GPS antenna height contributes to different GPS-L4 values with increasing on the physical conditions surroundings of the GPS receiver. This increase is happening while its amplitude is approximately fixed. The modeled GPS-L4 and variability of GPS-L4 values show a considerable increase in the frequency of corresponding trends when the snow depth is decreasing (analogous to increase in the GPS antenna height).

5) The comparison of daily GPS-L4 values in BAKE and KUUJ sites for different climatic conditions in different months shows a sizable difference between GPS-L4 values for the snow accumulation and snow melting with bare soil and stable snow on the ground. The frequency of static condition (bare soil or stable snow depth) and the power spectral density (PSD) of the aforementioned scenarios demonstrate that the fraction power/frequency of coherence functional subtracting for snow accumulation and snow melting is also larger than the similar value for the bare soil and stable snow on the ground in the different satellite elevation angles.

The results in this study present the effects of snow depth changes on the GPS-reflected signals, and other factors should be taken into account in the future, e.g., the surface characteristics polarization. It is clear to show that different snow types may result in different reflected signals, especially in the range of PSD values. Additionally, the surface topography (flatness) and density homogeneity of snow-covered layer are ignored here due to more complexity. Therefore, further studies should be further investigated and considered for various types of snow with their temporal physical conditions.

\section{REFERENCES}

[1] S. G. Jin, T. van Dam, and S. Wdowinski, "Observing and understanding the Earth system variations from space geodesy," J. Geodyn., vol. 72, pp. 1-10, Dec. 2013, doi: 10.1016/j.jog.2013.08.001.

[2] S. G. Jin and G. P. Feng, "Large-scale variations of global groundwater from satellite gravimetry and hydrological models, 20022012," Global Planet. Change, vol. 106, pp. 20-30, Jul. 2013, doi: 10.1016/j.gloplacha.2013.02.008.

[3] T. A. Warner, G. M. Foody, and D. Nellis, The SAGE Handbook of Remote Sensing. Newbury Park, CA, USA: SAGE, 2009, pp. 397-411.

[4] E. Rignot and P. Kanagaratnam, "Changes in the velocity structure of the Greenland ice sheet," Science, vol. 311, no. 5763, pp. 986-990, Feb. 2006, doi: 10.1126/science.1121381.

[5] F. Scire-Scappuzzo and S. N. Makarov, "A low-multipath wideband GPS antenna with cutoff or non-cutoff corrugated ground plane," IEEE Trans. Antennas Propag., vol. 57, no. 1, pp. 33-46, Jan. 2009, doi: 10.1109/TAP.2008.2009655.

[6] C. Zuffada, A. Fung, J. Parker, M. Okolicanyi, and E. Huang, "Polarization properties of the GPS signal scattered off a wind-driven ocean," IEEE Trans. Antennas Propag., vol. 52, no. 1, pp. 172-188, Jan. 2004, doi: 10.1109/TAP.2003.822438.

[7] L. I. Basilio, R.L. Chen, J.T. Williams, and D. R. Jackson, "A new planar dual-band GPS antenna designed for reduced susceptibility to low-angle multipath," IEEE Trans. Antennas Propag., vol. 55, no. 8, pp. 2358-2366, Aug. 2007, doi: 10.1109/TAP.2007.901818.

[8] N. Rodriguez-Alvarez et al., "Snow thickness monitoring using GNSS measurements," IEEE Geosci. Remote Sensing Lett., vol. 9, no. 6, pp. 1109-1113, Jun. 2012, doi: 10.1109/LGRS.2012.2190379.

[9] S. G. Jin, G. Feng, and S. Gleason, "Remote sensing using GNSS signals: Current status and future directions," Adv. Space Res., vol. 47, no. 10, pp. 1645-1653, May 2011, doi: 10.1016/j.asr.2011.01.036. 
[10] J. L. Garrison and S. J. Katzberg, "The application of reflected GPS signals to ocean remote sensing," Remote Sens. Environ., vol. 73, no. 2, pp. 175-187, Aug. 2000, doi: 10.1016/S0034-4257(00)00092-4.

[11] R. N. Treuhaft, S. T. Lowe, C. Zuffada, and Y. Chao, "2-cm GPS altimetry over Crater Lake," Geophys. Res. Lett., vol. 28, no. 23, pp. 4343-4346, Dec. 2001, doi: 10.1029/2001GL013815.

[12] J. S. Lofgren, H. Rüdiger, and J. M. Johansson, "Monitoring coastal sea level using reflected GNSS signals," Adv. Space Res., vol. 47, no. 2, pp. 213-220, Jan. 2011, doi: 10.1016/j.asr.2010.08.015.

[13] K. M. Larson et al., "Use of GPS receivers as a soil moisture network for water cycle studies," Geophys. Res. Lett., vol. 35, no. 24, L24405, pp. 1-5, Dec. 2008, doi: 10.1029/2008GL036013.

[14] S. G. Jin and A. Komjathy, "GNSS reflectometry and remote sensing: New objectives and results," Adv. Space Res., vol. 46, no. 2, pp. 111-117, Jul. 2010, doi: 10.1016/j.asr.2010.01.014.

[15] N. Rodriguez-Alvarez et al., "Soil moisture retrieval using GNSS-R techniques: Experimental results over a bare soil field," IEEE Trans. Geosci. Remote Sens., vol. 47, no. 11, pp. 3616-3624, Nov. 2009, doi: 10.1109/TGRS.2009.2030672.

[16] E. E. Small, K. M. Larson, and J. J. Braun, "Sensing vegetation growth with reflected GPS signals," Geophys. Res. Lett., vol. 37, no. 12, L12401, Jun. 2010, doi: 10.1029/2010GL042951.

[17] P. Ferrazzoli, L. Guerriero, N. Pierdicca, and R. Rahmoune, "Forest biomass monitoring with GNSS-R: Theoretical simulations," $A d v$. Space Res., vol. 47, no. 10, pp. 1823-1832, May 2011, doi: 10.1016/j.asr.2010.04.025

[18] K. M. Larson, "A new way to detect volcanic plumes," Geophys. Res. Lett., vol. 40, no. 11, pp. 2657-2660, Jun. 2013, doi: 10.1002/grl.50556.

[19] K. M. Larson et al., "Can we measure snow depth with GPS receivers?," Geophys. Res. Lett., vol. 36, no. 17, L17502, pp. 1-5, Sep. 2009, doi: 10.1029/2009GL039430.

[20] E. Gutmann, K. M. Larson, M. Williams, F.G. Nievinski, and V. Zavorotny, "Snow measurement by GPS interferometric reflectometry: An evaluation at Niwot Ridge, Colorado," Hydrol. Process., vol. 26 , no. 19, pp. 2951-2961, Sep. 2012, doi: 10.1002/hyp.8329.

[21] S. G. Jin and N. Najibi, "Sensing snow height and surface temperature variations in Greenland from GPS reflected signals," Adv. Space Res., vol. 53, no. 11, pp. 1623-1633, Jun. 2014, doi: 10.1016/ j.asr.2014.03.005.

[22] M. Wiehl, B. Legresy, and R. Dietrich, "Potential of reflected GNSS signals for ice sheet remote sensing," Prog. Electromagnet. Res., vol. 40, pp. 177-205, 2003, doi: 10.2528/PIER02102202.

[23] M. D. Jacobson, "Dielectric-covered ground reflectors in GPS multipath reception-Theory and measurement," IEEE Geosci. Remote Sens. Lett., vol. 5, no. 3, pp. 396-399, Jul. 2008, doi: 10.1109/LGRS.2008.917130.

[24] F. G. Nievinski and K. M. Larson, "Forward and inverse modeling of GPS multipath for snow depth estimation, I: Formulation and simulations," IEEE Trans. Geosci. Remote Sens., vol. 52, no. 10, pp. 6555-6563, Oct. 2014, doi: 10.1109/TGRS.2013.2297681.

[25] F. G. Nievinski and K. M. Larson, "Forward and inverse modeling of GPS multipath for snow depth estimation, II: Application and validation," IEEE Trans. Geosci. Remote Sens., vol. 52, no. 10, pp. 6564-6573, Oct. 2014, doi: 10.1109/TGRS.2013.2297688.

[26] J. L. McCreight, E. E. Small, and K. M. Larson, "Snow depth, density, and SWE estimates derived from GPS reflection data: Validation in the western U. S.," Water Resour. Res., vol. 50, pp. 6892-6909, Aug. 2014 doi: 10.1002/2014WR015561.

[27] M. Ozeki and K. Heki, "GPS snow depth meter with geometry-free linear combinations of carrier phases," J. Geod., vol. 86, no. 3, pp. 209-219, Mar. 2012, doi: 10.1007/s00190-011-0511-x.

[28] A. Leick, GPS Satellite Surveying. Hoboken, NJ, USA: Wiley, 2004, pp. $1-464$.

[29] N. Najibi and S. G. Jin, "Physical reflectivity and polarization characteristics for snow and ice-covered surfaces interacting with GPS signals," Remote Sens., vol. 5, no. 8, pp. 4006-4030, Aug. 2013, doi $10.3390 / \mathrm{rs} 5084006$
[30] B. Hofmann-Wellenhof, H. Lichtenegger, and J. Collins, Global Positioning System: Theory and Practice, New York, NY, USA: Springer, 2001, pp. 1-382.

[31] S.G. Jin and N. Najibi, "Surface scattering characteristics and snow accumulating-melting behaviors from GNSS reflectometry," in Proc. Progress Electromagn. Res. Symp. (PIERS), Guangzhou, China, Aug. 25-28, 2014, pp. 1401-1405.

[32] R. B. Blackman and J. W. Tukey, The Measurement of Power Spectra From the Point of View of Communication Engineering. New York, NY, USA: Dover Publications, 1958, pp. 1-190.

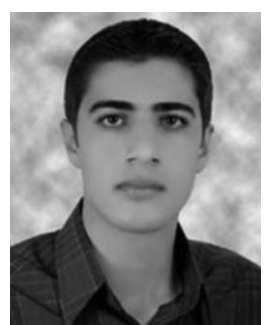

Nasser Najibi was born in Iran, in April 1989. He received the B.Sc. degree in surveying and geomatics from the University of Tehran, Tehran, Iran in 2011. He is currently pursuing the Master's degree at the Shanghai Astronomical Observatory, Chinese Academy of Sciences, Shanghai, China.

His research interests include satellite navigation, space geodesy, and GNSS-reflectometry.

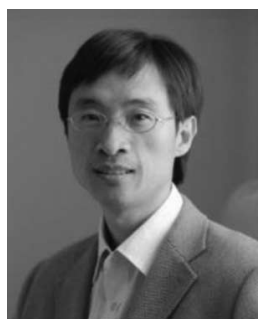

Shuanggen Jin (M'05) was born in Anhui, China, in September 1974. He received the B.Sc. degree in geodesy/geomatics from Wuhan University, Wuhan, China, in 1999, and the Ph.D. degree in GNSS/geodesy from the University of Chinese Academy of Sciences (CAS), Beijing, China in 2003.

$\mathrm{He}$ is currently a Professor with the Shanghai Astronomical Observatory, CAS, Shanghai, China, and Bulent Ecevit University, Zonguldak, Turkey. He has authored 250 papers in JGR, IEEE, EPSL, GJI, Icuras, JG, Proceedings etc., 7 books/monographs, and holds 8 patents/software copyrights. His research interests include satellite navigation, remote sensing, satellite gravimetry, space geodesy, and planetary exploration.

Prof. Jin has been a President of International Association of Planetary Sciences (IAPS) (2013-2015), President of International Association in CPGPS (2016-present), President of the IAG Sub-Commission 2.6 (20112015), Editor-in-Chief of International Journal of Geosciences (2010-present), Associate Editor of IEEE TRANSACtions on Geoscience and Remote SEnsing, Advances in Space Research (2013-present), and Journal of Navigation (2014-), and Editorial Board member of Journal of Geodynamics (2014-) and Planetary and Space Science (2014-). He is the recipient of the Special Prize of KASI (2006), 100-Talent Program of CAS (2010), Fellow of IAG (2011), Fu Chengyi Youth Sci. and Tech. Award (2012), Liu Guangding Geophys. Youth Sci. and Tech. Award (2013), etc.

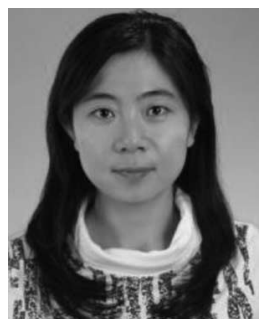

Xuerui Wu was born in Neimenggu, China, in June 1981. She received the B.Sc. degree in computer science from Neimenggu Normal University, Huhot, China, in 2003, M.Sc. degree in remote sensing from Beijing Normal University, Beijing, China, in 2006, and the Ph.D. degree in remote sensing from Dalian Marine University, Dalian, China, in 2012.

She is currently an Assistant Professor with Shanghai Astronomical Observatory, Chinese Academy of Sciences, Shanghai, China. Her research interests include GNSS Reflectometry and its

applications. 